\title{
La Iglesia católica chilena en el siglo XIX. Encuentros y desencuentros con la modernidad filosófica ${ }^{1}$
}

\author{
Ana María Stuven \\ INSTITUTO DE HISTORIA \\ PONTIFICIA UNIVERSIDAD CATÓLICA DE CHILE \\ astuven@uc.cl
}

\begin{abstract}
Resumen: El artículo trata sobre la relación entre religión y filosofía moderna en tres momentos de la historia del siglo XIX chileno. Se plantea que la fundación de La Revista Católica en 1843 marca un momento de inflexión en la postura eclesiástica desde la defensa de su espacio jurisdiccional hacia su ingreso en la esfera pública como interlocutor en el campo ideológico impuesto por la civilización moderna. El acceso de Pío IX al papado inauguró un nuevo momento de conflictos entre Iglesia y Estado en Chile por su condena al liberalismo.
\end{abstract}

Palabras clave: Religión, filosofía, Chile, siglo XIX, catolicismo.

Abstract: The article discusses the relationship between religion and modern philosophy in three moments of Chilean 19th C history. It asserts that with the foundation of La Revista Católica in 1843 the attitude of the clergy reaches a turning point moving from its concentration on the defense of its jurisdictional powers to its participation in the public sphere as interlocutor in the ideological field imposed by modern civilization. The arrival of Pius IX as Pope, condemning liberalism, inaugurated a new moment of conflicts between church and state

Keywords: Religion, philosophy, Chile, 19thC, Catholicism.

José Ignacio Cienfuegos, nuevo gobernador del Obispado de Santiago, fue el primero en jurar la Independencia de Chile en 1818. "Y así lo juro porque creo en mi conciencia que esta es la voluntad del Eterno"2.

$1 \quad$ Este artículo contó con el apoyo del proyecto Fondecyt 1130771.

2 R. Krebs, La Iglesia de América Latina en el siglo XIX (Ediciones P. Univ. Católica de Chile, 2002) 57. 
La Constitución provisoria, jurada ese mismo año, disponía: "La religión católica, apostólica, romana, es la única y exclusiva del Estado de Chile”. Se prohibía el culto público de cualquier otra devoción.

La religión católica y parte del clero, aunque minoritaria en ese momento, se asociaba así al momento fundacional de la república. El quiebre político con la Madre Patria no había acarreado ni una ruptura en la estructura social del poder ni tampoco en las creencias que adoptaba el nuevo Estado. Ambas continuidades sin duda aliviaron a una clase dirigente que tomaba conciencia de vivir un nuevo tiempo de futuro incierto y abierto. Se trataba de una gran empresa, que requería instaurar un nuevo orden; nuevas expectativas se abrían ante sus ojos; el presente aparecía como un escenario transitorio, donde inevitablemente entrarían en escena nuevos elencos con guiones desconocidos. Parafraseando a Koselleck, los contemporáneos debían percibir que su espacio de experiencia, marcado por la pertenencia al orbe hispano se distanciaba de su horizonte de futuro, librado a sus designios aunque sometido a un diseño preestablecido ${ }^{3}$. La república traía consigo una carga de imposiciones político-conceptuales que con razón se percibían como revolucionarias. La sanción del pueblo como nuevo soberano, con todas sus implicancias, inauguraba una asimetría entre la experiencia y la expectativa. No era menor el desafío de tener que fundar un gobierno sobre los principios de la soberanía popular, la ciudadanía, y la representación. En ese contexto, la promesa política se desplegaba en un clima de incertidumbre, en el cual la desintegración social y la anarquía se convertían en fantasmas que acechaban.

Desatendiendo por momentos la agenda de problemas político-religiosos que inauguraba, la revolución se cargó de significación positiva al asignársele, por sus defensores, la condición de manifestación de la voluntad liberadora de Dios. La crítica histórica de la monarquía hispana y su pretendida cristiandad colonizadora, contribuyeron en los inicios a legitimar la república como encarnación de los valores evangélicos, y a hacerle el contrapeso a las tendencias absolutistas que defendían el derecho divino de los reyes ${ }^{4}$. No obstante el rechazo a la dependencia

3 R. Koselleck, "Dos categorías históricas: 'espacio de experiencia' y 'horizonte de expectativa'” en Futuro Pasado. Para una semántica de los tiempos históricos (Paidós, Barcelona, 1993) cap. XIV333-357.

4 J. De Ferrari - M. Salinas, "Las ideas teológicas en Chile", en Pablo Richard (editor), Materiales para una historia de la teología en América Latina (VIII Encuentro Latinoamericano de CEHILA, Lima, 1980) 113. 
política de España, la herencia cultural, especialmente la religiosa, no sufrió mayor desafección en los primeros años republicanos. Sin embargo, aunque no se reconociese explícitamente, esa independencia política afectaba directamente lo religioso, debido a que desataba problemas jurisdiccionales que en el Antiguo Régimen estaban resueltos por la concesión papal del patronato, la cual permitía al monarca controlar la jurisdicción eclesiástica en América. A pesar de ello, ya en el período borbónico hubo tensiones por las políticas que limitaban la autonomía del clero y controlaban a los regulares ${ }^{5}$. Reemplazado el poder monárquico por una nueva forma política, era natural que aflorara nuevamente el conflicto al tener el poder eclesiástico que constituirse como un interlocutor separado del Estado, defender su independencia y autoridad sobre los símbolos religiosos, así como disputar su lugar institucional y el del clero en el nuevo escenario donde la legitimación por lo sagrado dejaba de ser requisito para las instituciones políticas ${ }^{6}$. Surgía así un problema de poder inédito, aunque en un primer momento la mayoría de los Estados independientes no pretendieran disociarse de la religión. Como aclara Roberto Di Stefano, el desafío de los nuevos Estados hispanoamericanos de formar una nueva esfera política implicó también que la Iglesia asumiera la función de crear una esfera propia para la religión ${ }^{7}$. Los Estados querían continuar con el patronato (Bolívar, O’Higgins, Sucre, Santander quisieron poner en práctica el patronato bajo nuevas formas jurídicas.) De hecho, consideraban a la institución eclesiástica como parte del Estado ${ }^{8}$. Intentaban mantener de su lado el auxilio de la religión, al mismo tiempo que imponían un modelo que subordinaba a la Iglesia en algunas de sus funciones, enfrentaban la incomunicación con Roma y se entrometían directamente con el clero. Los roces institucionales aparecieron tempranamente, especialmente por demandas de

\footnotetext{
5 R. Herr, España y la revolución del siglo XVIII (Aguilar, Madrid, 1979).

6 W. Taylor, Ministros de lo sagrado (El Colegio de Michoacan, México, 1999).

7 Distefano, R. 2012. “¿De qué hablamos cuando decimos "iglesia”? reflexiones sobre el uso historiográfico de un término polisémico", en Ariadna Histórica. Lenguajes, conceptos y metáforas 1 (2012) 195-220.

8 R. Distefano, El Púlpito y la Plaza (Siglo XXI, Buenos Aires, 2009); R. BlancarTE, "Dilemas del pasado y retos del presente para la laicidad en América Latina", en A. STUVEn (editora), La religión en la esfera pública chilena: ¿Laicidad o secularización? (Ed. Univ. Diego Portales, Santiago, 2014). Del mismo autor, "Laicidad y secularización en México", en J. Bastian, La modernidad religiosa: Europa latina y América Latina en perspectiva comparada (FCE, México, 2004).
} 
tolerancia religiosa para inmigrantes protestantes y por aspectos de administración eclesiástica. Sin embargo, manifestaciones hostiles de por medio, ambos poderes dialogaron conscientes de su mutua necesidad'.

Unidos constitucionalmente, en Chile el poder civil y eclesiástico emprendieron un largo y pedregoso camino cuyas bifurcaciones enfrentaban los principios y orientaciones que cada uno representaba. El poder eclesiástico acudió a la religión como fuente de su autoridad; el Estado a la república y los principios de la modernidad política. En las primeras décadas republicanas se convivió en la aceptación eclesiástica del tutelaje de la autoridad civil y el reconocimiento por parte del Estado de su responsabilidad sobre la Iglesia ${ }^{10}$. En esos años, el discurso eclesiástico concentró sus esfuerzos retóricos en la defensa de la jurisdicción eclesiástica, en la crítica hacia la filosofía racionalista que provenía del siglo XVIII, y en afirmar su superioridad en materias de moral respecto de otras denominaciones. De ahí que los conflictos giraran sobre todo alrededor de los temas derivados del patronato y de la tolerancia religiosa ${ }^{11}$. Desde los años 30 en adelante, especialmente en la figura del obispo Manuel Vicuña, se puede detectar que la Iglesia comienza a agregar a su cruzada por limitar la autoridad del Estado, la lucha por su independencia, expresada, por ejemplo, en la separación del Seminario del Instituto Nacional ${ }^{12}$.

En este trabajo plantearemos que la fundación de La Revista Católica en 1843 marca un momento de inflexión en la postura eclesiástica. Ella se constituye como un espacio de opinión sobre la influencia social de la

9 S. Vergara Quiroz, “Iglesia y Estado en Chile, 1750-1850”, en Historia 20 (1985) 319-362; J. Fernández Sebastián, "Toleration and freedom of expression in the Hispanic world between Enlightenment and Liberalism", en Past and Present 21 (2011) 159-197.

10 Ver G. Cid, "Religión, legitimidad política y esfera pública en Chile: el tránsito de la monarquía a la república (1808-1833), en A. STUVEN (editora), La religión en la esfera pública... Esta convivencia todavía perduraba en 1845 cuando la autoridad eclesiástica aceptó la designación de Rafael Valentín Valdivieso como Arzobispo de Santiago.

11 La filosofía de la Ilustración era conocida en Hispanoamérica desde mediados del siglo XVIII, y católicos laicos seguían a Campomanes y Jovellanos. Entendían que los derechos se podían discernir mediante la razón, y también leían a Hobbes, Locke, Montesquieu, Rousseau, Paine y Raynal. Ver J. Lynch, Dios en el Nuevo Mundo. Una historia religiosa de América Latina (Crítica, Barcelona, 2012).

12 Ambas instituciones permanecían unidas desde 1819. Ver J.A. Rodríguez Aldea, La reunión del colegio Seminario al Instituto Nacional justificada en el hecho y en el Derecho (Imprenta del Gobierno, Santiago, 1819) 54. 
religión, y de toma de posición en un debate intelectual donde el liberalismo ganaba terreno. Dejando atrás su condena a la filosofía racionalista, por su intermedio el catolicismo buscó insertarse como interlocutor en el campo ideológico impuesto por la civilización moderna ${ }^{13}$. Se trató de una toma de conciencia por parte del clero de que la discusión sobre el campo religioso se trasladaba hacia la cultura, lo cual aconsejaba tomar el guante en el espacio de las ideas, sin por ello abandonar el tema jurisdiccional. La fecha es simbólica, pues la década de 1840 representa un momento que podemos calificar de aceleración histórica ${ }^{14}$, por la percepción que tienen los actores de vivir un momento inédito y precursor, abierto hacia el progreso y distante del pasado. En ese contexto, el concepto de progreso se hizo indispensable para registrar la experiencia de cambio. Una nueva generación, nacida con la independencia y que alcanzaba su madurez al alero del maestro Andrés Bello, se avizoraba como una incipiente república de las letras. Atentos sus miembros a los fenómenos europeos, especialmente franceses, alentaron un debate público en torno a las promesas de progreso indefinido que prometía la utopía liberal, y desencadenaron una lucha por la propiedad del concepto.

El poder eclesiástico, consciente del ingrediente secularizador que subyacía, enfrentó el reto con decisión, y argumentó apropiándose y resemantizando en clave teológica los mismos conceptos que se barajaban para criticarlo como enemigo del racionalismo. Sostenemos, entonces, que en los años 40 la Iglesia chilena cambió su estrategia defensiva para tomar como bandera propia el discurso civilizador y progresista en contra de las posturas que exigían su expulsión del Estado en nombre de los mismos principios. La filosofía, que desde el siglo XVIII los clérigos habían desacreditado como enemiga de la teología, recibió ahora su reconocimiento como disciplina, y se tornó un concepto contingente, utilizado para múltiples argumentaciones y finalidades, entre ellas, amistarla nuevamente con la teología ${ }^{15}$. El encuentro, no exento de debate, fue de corta duración.

13 La Revista Católica, "Prospecto", 9 de marzo de 1843.

14 R. Koselleck, Aceleración, prognosis, secularización (Pretextos. Valencia, 2003); O. Remaud, "Pequeña filosofía de la aceleración histórica", en F. Oncina (editor) Teorías y prácticas de la historia conceptual (CSIC/Plaza y Valdés, Madrid, 2009).

15 La relación entre filosofía y teología está presente en los inicios del cristianismo. pues la matriz de la cual bebieron los primeros teólogos entroncaba su reflexión con la filosofía. 
El anticlericalismo de jóvenes liberales, alimentados intelectualmente por el "neocatolicismo" francés, las nuevas corrientes filosóficas que cundían en Europa, y extremado luego de los sucesos europeos de 1848, encontró la oposición de un clero crecientemente ultramontano e identificado incondicionalmente con la línea trazada por el papado, desde que Gregorio XVI condenara las ideas liberales sustentadas por Felicité de Lamennais y su periódico L’Avenir en las encíclicas Mirari Vos de 1832 y Singulari Nos de 1834. Los choques más graves en toda América Latina se dieron en la década de 1850, coincidiendo en Chile con los conflictos entre Estado e Iglesia durante el gobierno de Manuel Montt. En esos años, ante la evidencia que constituyó la negativa de la Santa Sede para extender el derecho a patronato a los nuevos Estados, las elites liberales latinoamericanas reorientaron sus posiciones, radicalizando su discurso antieclesiástico. Estaban en juego no solo el control de los nombramientos eclesiásticos, la reglamentación y el ordenamiento de la vida interna de la Iglesia, sino también, y muy importante, el control de los bienes e ingresos eclesiásticos. Identificamos la década de 1860 como el momento en que Iglesia y Estado se constituyen como dos frentes antagónicos, marcada por cierto por las propuestas parlamentarias contra el unanimismo católico, las políticas del pontificado de Pío IX y las condenaciones vaticanas al liberalismo.

Las polémicas de la Generación llamada de 1842 son un excelente laboratorio para experimentar la innovación conceptual que se despliega sincrónicamente en los discursos periodísticos religioso y laico desde la asunción al mando presidencial del héroe de la guerra, general Manuel Bulnes, en $1841^{16}$. No deja de ser sorprendente la escasa atención que ha prestado la historiografía a los intentos de armonizar el catolicismo con la modernidad ideológica en la primera mitad del siglo $\mathrm{XIX}^{17}$, tal vez porque su mirada ha estado principalmente enfocada hacia la dimensión institucional. Como consigna Brian Connaughton, en la literatura ha prevalecido la idea de que la religión es en general un obstáculo a la

16 Ver A. Stuven, La Seducción de un Orden: Las elites y la construcción de Chile en las polémicas culturales y políticas del siglo XIX (Ed. P. Universidad Católica de Chile, Santiago, 2000).

17 S. Serrano, ¿Qué hacer con Dios en la República? Política y secularización en Chile (1845-1885), FCE (Santiago: FCE, 2008). Su libro trabaja el tema explorando el proceso de adecuación del catolicismo y la Iglesia a la modernidad republicana. 
modernización ${ }^{18}$. Sin embargo, aun oponiéndose a los cambios que afectaban su rol en el Estado, incluso combatiendo a sus autoridades y asumiendo posturas refractarias a las propuestas de quienes se declaraban liberales, el discurso católico adoptó e utilizó los mismos conceptos de manera de demostrar la compatibilidad entre modernidad y religión ${ }^{19}$. Lo anterior sugiere la posibilidad de hablar de una modernidad religiosa, entendida, como propone Mallimaci, como "continuo proceso de transformación, recomposición y reorganización del campo religioso" ${ }^{20}$. Ello permite caracterizar la polisemia conflictiva de los conceptos en disputa, particularmente los de civilización y progreso, y, como mostró Koselleck escribiendo sobre la Revolución Francesa, que muchos conceptos políticos adoptaron un carácter performativo, en su afán por controlar el diseño y pronosticar el futuro ${ }^{21}$.

La guerra por las palabras, usando la feliz expresión de Javier Fernández Sebastián ${ }^{22}$, enfrentó el lenguaje teológico con el político ${ }^{23}$. En una época percibida como seminal, de aurora o crepúsculo, la definición de los términos deviene crucial, y la polaridad en la cual estos se despliegan parece parte de un mundo que debe reconocer que el tránsito es movimiento. Siguiendo a Quentin Skinner, estos años sirven de laboratorio para demostrar una vez más que los conceptos políticos asumen diversos

18 B. Connaughton, "La nueva historia política y la religiosidad: ¿Un anacronismo en la transición?”, en G. PALACios (coord.), Ensayos sobre la nueva historia política de América Latina, siglo XIX (Colegio de México, México, 2007).

19 B. Connaughton, 177. También F. Mallimaci, "Catolicismo y liberalismo: Las etapas del enfrentamiento por la definición de la modernidad religiosa en América Latina”, en J. BASTIAN (coord.), La modernidad ... Entre quienes sostienen que la Iglesia se opuso a la modernidad, J. LYNCH, Dios en el... 147, aunque reconoce que en Chile había sacerdotes y laicos abiertos a las ideas de libertad e igualdad, 198.

20 F. Mallimaci, "Catolicismo..." 19. La religión habría perdido su rol como función política y estructurante del espacio social pero no su función subjetiva, identitaria y cultura. Ver M. Gauchet, The disenchantment of the world. A political history of religion (Princeton University Press, Princepton, 1997); O. BobINEAU, Le religieu et le politique: Douze réponses du Marcel Gauchet (Desclée de Brouwer, Paris, 2010).

R. Koselleck, Aceleración...

22 J. Fernández Sebastián, "Guerra de palabras. Lengua y política en la revolución de España”, en P. Rújula-Jordi Canals (eds.), Guerra de Ideas. Política y cultura en España de la guerra de la independencia (Marcial Pons; Madrid, 2011).

23 F. X. Guerra, "Hacia una nueva historia política", en Anuario IEHS (IEHS, París, 1989). El autor plantea que recién en el siglo XVIII surge un lenguaje propio de la política facilitando el surgimiento del conflicto. 
significados en función de la contingencia en la cual operan; que "cualquier enunciado es de manera ineludible la encarnación de una intención particular, en una oportunidad particular, dirigida a la solución de un problema particular" ${ }^{24}$.

En las páginas que siguen intentaremos identificar tres momentos de encuentros y desencuentros entre la Iglesia católica y la filosofía moderna. En el primero, se examinan las dificultades de un diálogo en el cual el clero postindependencia prioriza la búsqueda de su estatus institucional al interior del nuevo sistema político, y cuyas vinculaciones con la filosofía racionalista parecían imposibles. En el segundo, identificaremos ese corto momento de inflexión en los términos del debate, y que representan los primeros años de La Revista Católica. El acceso de Pío IX al trono de Pedro inauguró un nuevo momento de profunda repercusión en los conflictos entre Iglesia y Estado en Chile por su condena al liberalismo y su influencia sobre las posturas ultramontanas y antimodernas de sectores dominantes en el clero chileno.

\section{LOS PELIGROS DE LA FILOSOFÍA: EL DESENCUENTRO}

Los primeros argumentos clericales para defender teológicamente su espacio de poder político giraron alrededor de su condición de "potestad emanada de Dios" 25 . El discurso esgrimido en las primeras décadas después de la independencia enfatizó la preponderancia del poder eclesiástico por sobre el político, sin por ello renunciar a la adhesión a la república como régimen político que debía reemplazar a la monarquía. Su cruzada estuvo encaminada a impedir toda intromisión del poder político, especialmente desde que O’Higgins desafió su autoridad al recluir o desterrar a los religiosos que predicaron durante la Reconquista contra los patriotas, al establecer modificaciones en la composición del Cabildo Eclesiástico de Santiago y dictar el conocido Estatuto Provisional, o al promover la unión entre el Seminario y el Instituto Nacional. Esto último en un claro mensaje de reprobación hacia la formación "supersticiosa” del clero ${ }^{26}$. El periodismo fue un recurso al que se acudió y

24 Q. SKInNER, "Significado y comprensión en la historia de las ideas", en Prismas 4 (2009) 149-191.

25 "El Pensador Político-Religioso", en Colección de Antiguos Periódicos, 1824-1825 (Editorial Nascimento, Santiago) 279.

26 J. A. Rodríguez Aldea, La Reunión... 
utilizó como medio para el debate de ideas que tímidamente se instalaba entre la opinión pública letrada; el clero enfatizando su rechazo a una comprensión del concepto de filosofía en su versión ilustrada, entendido como desafío a la religión y a la institución eclesiástica y, en consecuencia, como aliado en la defensa de las prerrogativas estatales. El Observador Eclesiástico representó la postura. Circuló entre junio y diciembre de 1823, con ocasión del conflicto por la reforma de regulares. También El Pensador Político-Religioso de 1825, decidido a "[...] deslindar con toda imparcialidad lo que es propio de la Religión y de la Iglesia, y lo que pertenece al Estado [...]"27. Redactor de este último fue el Pbro. Justo Donoso. "El Estado está en la Iglesia, de otro modo no sería ni se diría estado cristiano. Más si el Estado es cristiano, lejos de poderse arrogar el príncipe una autoridad y jurisdicción sobre la Iglesia, está sujeto a las leyes eclesiásticas; ni puede sacudir su dependencia, mucho menos hacerse superior, sin trastornar la religión por su fundamento"28. Respetada esa superioridad, el beneficio recaerá sobre la seguridad pública y ambos poderes podrán vivir en armonía. "Las dos potestades aunque heterogéneas por sí, están dispuestas por una providencia especial de modo que la una necesite de la otra" ${ }^{29}$. No obstante, en el terreno de las prácticas políticas, como reza otro artículo, ambas esferas deben mantener sus propias atribuciones. A la jurisdicción eclesiástica corresponde “... la doctrina, la disciplina, la administración de los sacramentos, la ordenación de los ministros, su misión, y todo lo que concierne a la fe y al ejercicio del culto”. Al Estado en cambio, “... la policía, la propiedad, la paz, la guerra y todo lo que mira e interesa a la tranquilidad, no menos pública que privada". También se reconoce un área "mixta", sobre la que se reconoce disputa, pero sobre la cual no hay discusión: debe prevalecer siempre la potestad eclesiástica "como más digna y más propia y adaptada para el fin”. A este ámbito pertenece la moral, ante la cual el Estado no debe ser indiferente, aunque debe reconocer que esta se defiende solo "mediante la energía de la Religión"30. En el contexto de la lucha jurisdiccional, esa área llamada mixta por el articulista corresponde al espacio que trasciende lo jurídico hacia lo doctrinario y lo político, un

\footnotetext{
27 "El Pensador Político-Religioso", No 1, Prospecto, Santiago: 23 de marzo de 1825, en Colección de Antiguos Periódicos... 278.

28 "El Pensador..." 281.

29 "El Pensador...", 18 de abril de 1825, 3292.

30 "El Pensador...", 26 de abril de 1825, 4297.
} 
campo que diagnosticó previsoramente como en disputa desde que los "philosophes" se emanciparan de la tutela eclesiástica.

La postura es enfática: en el plano doctrinario que dictamina sobre aspectos morales, la interpretación debe quedar en manos de la institución eclesiástica; no debe existir pensamiento ni filosofía al margen de sus dictados. Por ejemplo, en 1822, a raíz de las conjeturas sobre las causas del terremoto que asoló a Valparaíso en noviembre de ese año, se inició una polémica entre quienes le atribuían explicaciones científicas y quienes le asociaron a un castigo divino ${ }^{31}$. Desde El Observador Eclesiástico terció fray Tadeo Silva a favor de la intervención de la ira de Dios por los vicios de la población. Entre estos estaría la lectura de "libros irreligionarios (sic), que corrompen la moral", refiriéndose a los escritos filosóficos que inspiraban a sus adversarios en la polémica. Exhortó finalmente al pueblo de Dios afirmando, en clara alusión a Camilo Henríquez: "No os dejéis seducir de los filósofos del tiempo: atended más bien a un filósofo rancio que os habla con la Sagrada Escritura y con los testimonios de los Santos Padres de la Iglesia"32.

La filosofía encarnaba el espíritu antirreligioso de la Ilustración francesa, lo que se desprende de las continuas descalificaciones hacia Rousseau, Condorcet, D’Alembert, Montesquieu y Voltaire ${ }^{33}$. En la filosofía, a juzgar por el combate que debió enfrentar, se focalizó el origen de las posturas que desafiaban no solo el poder clerical, sino su visión del mundo. El primer número de El Observador Eclesiástico se inició con referencias a la filosofía, distinguiendo aquella considerada "sana", representada por los periodistas "de nuestra revolución" que han buscado "uniformar la opinión pública [...] sacándonos del vil estado colonial al rango de nación soberana" ${ }^{4}$. Es decir, la sana filosofía es aquella que no

31 G. CID, “¿Castigo divino o fenómeno natural? Mentalidad religiosa y mentalidad científica en Chile en torno al terremoto de 1822", Revista de Historia y Geografía 30 (2014).

32 T. Silva, Aviso que da al pueblo de Chile un filósofo rancio (Imprenta Nacional, Santiago, 1823). El mismo fraile publicó Los Apóstoles del Diablo, en 1823 (Imprenta Nacional, Santiago).

33 Se puede conjeturar que la valoración del concepto de filosofía es polémico en el discurso católico de los año 20, especialmente comparando los textos arriba citados con los de Camilo Henríquez, quien apoyaba su defensa de la república justamente en los mismos "philosophes" ahora demonizados.

34 El Observador Eclesiástico, 21 de junio de 1823, en Colección..., 229. 
adopta posturas críticas sobre temas doctrinarios. Pero ya en el número siguiente, en medio de una confesión republicana, se denuncia a la "filosofía erguida" que "ataca diariamente este castillo inexpugnable fundado sobre la roca inmoble de la palabra del omnipotente" 35 . A la filosofía se le adjetiva como cruel, vana, orgullosa; se le acusa de esconder "[...] sus perversos designios de arruinar a la Iglesia Católica [...]"36. Se la asoció al naturalismo y al liberalismo, convirtiéndose así en el peor peligro para la vigencia de lo religioso.

Como queda de manifiesto, en la discusión antifilosófica, la autoridad eclesiástica evita contaminarla con eventuales interpretaciones antirepublicanas. Es decir, no se pone a prueba el régimen político, sino la interpretación que hace la filosofía de los principios que lo sustentan. Al respecto, El Pensador Político-Religioso publicó un largo artículo titulado "Religión: sus máximas conformes al espíritu republicano". Reconociendo que algunos filósofos podían interpretar que la religión no era compatible con la república debido al apoyo que había prestado a la monarquía en tiempos pasados, sostuvo el articulista: "Las máximas de la religión están de acuerdo con el espíritu democrático, y las repúblicas excluyendo la religión católica, substraerían a aquel gobierno del mayor y principal sostén". El argumento se apoya en que siendo el cristianismo el que predica la virtud y está en la base de la república, la democracia, asimilada conceptualmente con la república, "[...] no puede estar mejor fundada que sobre la religión misma". Aún más, siendo la libertad e igualdad las bases de la república, la religión cristiana "parece formada sobre este modelo y diseño". El concepto de libertad se entiende así como "... que a ninguno se impida hacer lo que las leyes permiten [...]". El de igualdad, como "... aquella igualdad que únicamente puede admitirse sin perturbar el orden”. La república es, en consecuencia, también útil por su capacidad para impedir las agitaciones y los desórdenes de la anarquía provocada por "... los que lisonjean su vanidad con la idea de la soberanía, para usurparla ellos en seguida". La referencia a la "idea de la soberanía" habla del rechazo a polemizar doctrinariamente sobre interpretaciones de los conceptos, amparándolas en el marco de la ley. No es, en consecuencia, la república un impedimento para la asociación armónica entre Estado e Iglesia, sino las posturas críticas de los

\footnotetext{
El Observador..., 2237.

El Observador..., 238.
} 
filósofos. "Son fanáticos en creerse nacidos para iluminar el universo; fanáticos en querer establecer una general igualdad entre los hombres, la cual no puede existir ni física ni moral; fanáticos al insinuar una libertad sin sumisión que produciría la ruina de la sociedad [...]"37. Son fanáticos también por antirreligiosos, como Voltaire. Ni siquiera en su lucha contra la superstición, una de las banderas esgrimidas por la filosofía, podrían estos tener éxito. "Cuando los filósofos consiguiesen fundar un gobierno, una república sin religión, no cerrarían por esto la puerta a la superstición. Si el pueblo no tiene las devociones religiosas que le deleitan y mueven a la virtud... tendrá verdadera y propiamente aquella superstición que los filósofos pretenden extirpar, y se la formará a su capricho" ${ }^{38}$. Por último, y para poner la lápida sobre la filosofía, el articulista afirmó que Voltaire y Hobbes eran grandes supersticiosos. Este último "no dormía solo por miedo a los muertos" 39 .

Entre las banderas que la filosofía de la Ilustración había enarbolado destacaba la tolerancia religiosa que desafiaba, en opinión del clero, el reconocimiento a su superioridad en el ámbito doctrinario y moral. Cuando se inició el debate en 1819, la autoridad eclesiástica lo enfrentó principalmente desde la perspectiva político-institucional, evitando las referencias doctrinarias que marcaron el debate posterior, en 1865. La polémica surgió cuando un grupo de protestantes de origen inglés solicitó autorización a Bernardo O’Higgins para comprar unos terrenos en Santiago y Valparaíso donde realizar ritos funerarios de acuerdo a su ritual. La autoridad chilena estuvo dispuesta a concederlo, apoyado en que ello no afectaba la catolicidad del Estado por tratarse de un espacio privado. En enero de 1820, un grupo de sacerdotes presentó a O’Higgins su Memorial teológico sobre la permisión de ritos protestantes en Chile, donde señalan estar en conocimiento de un decreto de diciembre de 1819 que habría concedido el permiso de sepultación según el rito protestante. El documento condenaba la concesión como una violación a la confesionalidad del Estado, reconocida por "el voto general del pueblo" en su Constitución ${ }^{40}$. El debate se reanudó a propósito de otro suceso, esta vez con motivo de la memoria que presentó al Congreso el

\footnotetext{
"Fanatismo" en El Observador..., 17 de mayo de 1825, 7: 318.

El Observador..., 28 de mayo de 1825, 8327.

El Observador..., 328.

40 "Memorial teológico sobre permisión de ritos protestantes en Chile", reproducido en los anexos de J. X. de Guzmán, Dictamen que a petición del gobierno da el pro-
} 
pastor bautista Diego Thompson, en 1822, sobre inmigración extranjera en Chile. Tratándose de un tema que involucraba a la autoridad eclesiástica, se solicitó a esta un informe, el que fue encomendado al franciscano José Javier de Guzmán, de reconocida trayectoria junto al bando patriota. Fue categórico en recomendar el rechazo de la solicitud, enrostrando a la autoridad que la Constitución le obligaba, como "uno de los primeros deberes de su celo religioso”, el jamás poner en contradicción los intereses de la patria y la religión ${ }^{41}$. El informe de Guzmán también consignaba el riesgo que la tolerancia traía para el orden político de la república, al plantear que los protestantes intentarían hacer proselitismo con la juventud, debilitando la religión, “y para conseguirlo con mayor facilidad, se levantarían en masa, tomarían las armas, harían correr arroyos de sangre humana, y no contentos con destruir los templos, en que damos religioso culto al Dios Eterno, se dirigirían a derribar el trono de nuestro político gobierno... No dudemos un momento, que si la religión se pierde, la patria debe sucumbir, y pasar al dominio de los extranjeros", señalaba amenazante ${ }^{42}$.

La siguiente discusión en torno a la tolerancia religiosa se produjo en 1825 , a propósito de la publicación en 1823, por Juan Egaña, de su Examen instructivo sobre la Constitución política de Chile, en el cual relacionaba la unidad moral y política del país. La reflexión del jurista surgía desde una visión de la historia que explicaba la sobrevivencia de los pueblos según la fortaleza de su religión. "La nación judaica", decía, había sobrevivido a las persecuciones porque "Dios se ha valido de este principio natural”. Europa, en cambio, “débil en religión”, tenía sus costumbres y patriotismo en decadencia. "Sin religión uniforme se formará un pueblo de comerciantes, pero no de ciudadanos", afirma$\mathrm{ba}^{43}$. Egaña profundizó su reflexión sobre el tema en su Memoria política sobre si conviene en Chile la libertad de cultos, publicada meses después, donde reafirmó el vínculo entre la libertad política y la religión, en el contexto de una polémica con José María Blanco White, quien, desde

vincial de San Francisco sobre la introducción de los extrangeros en Chile (Imprenta de D. Esteban Valle, Santiago, 1822), XII.

41 J. X. De Guzmán, Dictamen... 5.

42 J. X. De GuZmán, Dictamen... 21.

43 J. EgañA, "Examen instructivo sobre la Constitución política de Chile promulgada en 1823", en V. Letelier (editor) Sesiones de los Cuerpos Legislativos, 37 vols. L 8871908, tomo IX (1823) Anexo No 7, 31. 
Londres, había comentado tanto el Examen Instructivo como el texto de la Constitución de 1823, justificando su rechazo. "En una república religiosa descansan las leyes para la mayor parte de las acciones u omisiones morales en el freno de la religión que reprime o dirige las intenciones o disposiciones ocultas que pudieran preparar los delitos" ${ }^{\text {"4 }}$.

Este debate evidencia los primeros esbozos de una polémica más ideológica entre el liberalismo y el republicanismo inicial de la clase dirigente chilena, respecto de la contradicción entre la primacía de la libertad individual y el bien común, así como también la igualdad ante la ley. Es lo que queda claro en el opúsculo Reflexiones sobre los bienes y rentas eclesiásticas, y el daño que se dice proviene de ellos a la sociedad, donde, defendiéndose el derecho de propiedad apoyado en el "contrato social", y aun aceptando el carácter de "corporación secular" de las comunidades religiosas, el redactor del texto afirmó: “¿Pero, como puede un gobierno, cualquiera que sea, prescindir de la Religión? ¿Cómo pueden ponerse al par de los otros bienes los de la Iglesia que han sido siempre y por todos mirados como una porción más sagrada e inviolable?”. La pregunta surgía desde la convicción que el clero tendría, además del "derecho natural y civil”, el "derecho divino y eclesiástico". Incluso, agregaba, en el régimen actual, "el pueblo constituye la república, y el clero forma una parte la mejor y más sana del pueblo". Este debate, surgido a propósito de las críticas al exceso de bienes eclesiásticos, y del secuestro de los bienes a los regulares en 1824, terminó poniendo al clero en contra incluso de sus votos de pobreza, argumentando que su riqueza era necesaria para su independencia de los "seculares", y para "subvenir a los pobres" ${ }^{45}$.

A fines de la década de 1820 quedó abierto un escenario de disputa entre el Estado y la Iglesia católica por la tuición de asuntos que afectaban a la religión, el cual quedó postergado por la llegada al gobierno del grupo triunfador en la contienda que culminó en el triunfo conservador en Lircay. Los bienes de los regulares fueron devueltos en 1830. La impronta impuesta por la nueva autoridad, especialmente por el influjo de Diego Portales, privilegió la vinculación armoniosa con el clero en

44 J. M. Blanco White, Observaciones sobre varios periódicos y otros impresos hispanoamericanos y en particular sobre la Constitución Política de Chile de 1823 copiado del num 6 del Mensajero de Londres (Imprenta de la Biblioteca, Santiago, 1825) 12.

45 Reflexiones sobre los bienes y rentas eclesiásticas, y el daño que se dice proviene de ellos a la sociedad (Imprenta de la Independencia, Santiago, 1825). 
función de la preservación del orden social y público, debido al ascendiente que este tenía sobre los fieles. Siendo que en los primeros años de la década de 1830 el énfasis político principal era la consolidación del poder pelucón y el orden interno, la religión y su rol en la esfera pública no fueron cuestionados. No obstante, Manuel Vicuña, fiel al patronato, dio algunas luces sobre lo que sería el paso de la lucha por la preponderancia del poder eclesiástico sobre el civil a la cruzada por su independencia. En su primera pastoral apeló a la doctrina sobre los dos poderes, y declaró hacer "profesión de creer que la Iglesia es independiente del poder temporal en las cosas de religión", así como que a "los príncipes temporales" correspondía solo defender pero no conducir a la Iglesia en su tránsito terrenal ${ }^{46}$.

\section{LA CONCILIACIÓN ENTRE FILOSOFÍA Y TEOLOGÍA}

“¿Quién podrá desconocer los grandes destinos de la nueva era que hoy se abre para los chilenos, a vista del estado próspero del país y del impulso de vida y actividad que hoy recibe por todo? ¿ No está vivo entre nosotros el recuerdo de las desgracias y extravíos pasados, para que no sepamos apreciar y conservar los bienes presentes?” Andrés Bello, figura descollante en la vida intelectual chilena, y maestro de la Generación llamada de 1842, puso su natural elocuencia al servicio de las conmemoraciones de la llegada al poder de Manuel Bulnes, héroe victorioso de la reciente guerra contra la Confederación Perú-boliviana. El artículo fue publicado en el periódico oficial, El Araucano, el 18 de septiembre de 1841, cuando también se celebraba el aniversario de la independencia. Bello escogió esa ocasión festiva para expresar su percepción de que el país inauguraba una nueva época que significaba la superación de un pasado colmado de "desgracias" y "extravíos".

Francisco Bilbao, Jacinto Chacón, Salvador Sanfuentes, Manuel Antonio Tocornal, José Joaquín Vallejo, Pedro Félix Vicuña son algunos nombres destacados de la Generación; José Victorino Lastarria, especialmente notable por sus reflexiones sobre filosofía de la historia y su conciencia de tiempo acelerado. A ellos se suman los argentinos exiliados de Juan Manuel de Rosas. Domingo Faustino Sarmiento es uno de los grandes en estas lides, actuando como columnista de El Mercurio de

$\overline{46}$ Citada en R. Krebs, La Iglesia..., 139. 
Valparaíso y luego editor del primer diario santiaguino, simbólicamente llamado El Progreso.

Enfrentada a la nueva época, que algunos asimilan a un "resplandor (que) nos ofende todavía la vista...", como se escribe en El Mercurio, el 28 de octubre de 1843, la jerarquía eclesiástica fundó La Revista Católica, en 1843. En su Prospecto admitió el advenimiento de una nueva era en la cual "[...] todo parece presagiar la pronta realización de mejoras en los diversos ramos de la pública prosperidad [...]" ${ }^{47}$. Consciente que enfrentaba grandes desafíos, no solo de readecuar su posición en la sociedad republicana, sino de situarse en el contexto de una Iglesia que no contaba ya con el patrono español, y enfrentar una cultura chilena donde el liberalismo y la laicidad penetraban con vigor ${ }^{48}$, la jerarquía defendió sus posturas normativas en el campo de los valores sociales, culturales y políticos, asimilando la retórica y capacidad persuasiva del lenguaje, y luchando, sin esquivar, por la definición de los conceptos. Continuó defendiendo la libertad de la Iglesia frente al Estado, asoció la religión con la defensa del orden social, y se acercó a la Santa Sede tendiendo al ultramontanismo. También decidió abordar el problema filosófico, denunció la laicización de la sociedad y condenó ardientemente al liberalismo, al socialismo y al comunismo.

El discurso eclesiástico fue tributario del debate europeo, especialmente francés, en torno al progreso. A los traumas de la Revolución, la intelectualidad francesa había respondido con una revisión profunda de los presupuestos de la filosofía del siglo XVIII, formulando, entre 1818 y 1840 , nuevas interpretaciones de la doctrina de la libertad, críticas la mayoría al volterianismo de la tradición. Se condenaba su materialismo, y su reducción de la humanidad a la dimensión única de la naturaleza. La misma percepción de tiempo nuevo que identificó la Generación del 42 chilena había permeado los espíritus franceses especialmente desde la instauración de la monarquía de Julio. Chateaubriand, pluma fecunda y preferida entre los católicos chilenos, había resumido la sensación en una frase célebre: "Me he encontrado entre dos siglos, como en la confluencia de dos ríos; me he sumergido en sus aguas turbulentas, alejándome a mi pesar de la vieja ribera donde había nacido, nadando espe-

$47 \quad$ La Revista Católica, 1 de abril de 18431

48 Sobre la definición del concepto de laicidad, ver R. Blancarte, Dilemas... y F. Mallimaci, "Catolicismo...". 
ranzado hacia una orilla desconocida" ${ }^{49}$. Entre la esperanza y la angustia, una historia en permanente movimiento por delante, la inquietud intelectual se redireccionó hacia las aguas mansas donde el futuro pudiera desplegarse ajeno a los remolinos que tanto dolor habían causado. En el Imperio, Mme. De Stael y Benjamin Constant habían iniciado la restauración del ideal y refutado a Rousseau, identificando a un Dios providencial como conductor del progreso y en permanente diálogo con las inteligencias humanas para su desarrollo. Bajo la Restauración, los liberales que defendían el control del público sobre el gobierno, asignaron un lugar preponderante a la lucha de ideas, preparando la arena para el ingreso de quienes desde el catolicismo rechazaron la filosofía de las luces en nombre de una filosofía compatible con la religión. Autores como Ballanche y Chateaubriand buscaron asociar la filosofía de las Luces con el Evangelio, convertir la idea de cambio en ley de Dios, y demostrar la posibilidad de la libertad. De hecho, Chateaubriand, aunque menos religioso, acogió positivamente las posturas de Lamennais y su búsqueda de una formulación teológica de la idea del progreso. A ese grupo pertenecieron los "neocatólicos", escritores de fe católica que quisieron modificar la expresión tradicional de la fe para justificarla a los ojos de un público moderno, predicándolo de un modo nuevo, dando preeminencia al porvenir sobre el pasado ${ }^{50}$. En su visión, Dios estaría de lado de los valores modernos que la religión de los siglos precedentes había rechazado. Sus cultores pensaban que integrando a la religión en la corriente del movimiento, se garantizaría su posibilidad de sobrevivir en la nueva sociedad. Su estrategia, conservadora pero abierta al futuro, se proponía ser la tabla de salvación lanzada al remolino de las críticas a la Iglesia, buscando acomodar el catolicismo a la modernidad y asignando valor a la vivencia espiritual personal arraigada en el sentimiento. Se trataba sin duda de una difícil conciliación que justificó la disputa con el viejo dogma, y también que sus cultores, Lamennais principalmente, terminaran rechazando la jerarquía eclesial, e incluso la noción misma de Iglesia como autoridad distinta de la masa de los fieles. Su reinterpretación de la doctrina volvió su postura irreconciliable con el catolicismo, pues incluso la figura de Jesús y su divinidad fue sometida a una

49 Chateaubriand, "Mémoires d'outre-tombe" citado en P. Bénichou, El Tiempo de los Profetas. Doctrinas de la época romántica (Fondo de Cultura Económica, México, 2012) 119.

50 P. BÉNICHOU, El tiempo de... 
lectura nueva que presagió una ruptura con la fe tradicional. El papado, retornado a Roma después del exilio, y buscando fortalecer su jerarquía, asumió una actitud defensiva y condenatoria frente a todo intento de innovación. Como se señalara en páginas anteriores, Gregorio XVI, en su encíclica Mirari Vos de 1832, reafirmó el carácter inmutable de la Iglesia como institución divina, y condenó los intentos de Lamennais, Montalembert y Lacordaire de reconciliar catolicismo y liberalismo, así como la masonería.

A La Revista Católica, bajo el influjo del primer arzobispo de Santiago, Rafael Valentín Valdivieso, correspondió ser la tribuna donde se dieron a conocer las interpretaciones y posturas del clero chileno frente a los debates que agitaban a la Iglesia europea, especialmente francesa, así como la contextualización de los mismos en la escena y en los conflictos político-culturales del país. Como los neocatólicos en Francia, los redactores de la revista, citando a sus representantes, especialmente Lamennais y Chateaubriand, pero también a Guizot, buscaron compatibilizar la idea de progreso con el cristianismo. En el nuevo horizonte de expectativas que rechazaba el pasado en nombre de un futuro abierto, imprevisible e inevitable, la revista también buscó resignificar el concepto de filosofía para ponerlo en la dinámica del cambio, intentando dar por superados sus postulados antirreligiosos del XVIII. Como los neocatólicos, buscó conciliar el progreso con la acción de la Providencia, y reafirmó también el valor insustituible de la razón y de la inteligencia humana ${ }^{51}$. Se trataba de asignar a la religión un papel activo y positivo en la sociedad chilena, de reivindicar a la razón y el concepto de filosofía en su calidad de dependiente histórica y conceptualmente de la teología, de evitar las disputas con la Ilustración, y debatir con la apropiación liberal del concepto. "Los rayos de luz que la marcha progresiva del presente siglo esparce por todas partes, descubren cada vez con más claridad la benéfica influencia de la religión, y la misma filosofía que en tiempos aciagos osó despreciarla, guiada ahora por la razón y la experiencia, no trepida ya en confesar, que aquella es el mejor agente civilizador y el único que produce resultados positivos" 52 . En respuesta a Darwin, Comte y Fuerbach, se defendía el uso recto de la razón. A la incertidumbre de la transición, se respondía: "Los genios pensadores, después de sostener

51 J. De Ferrari - M. Salinas, Las ideas...

52 La Revista Católica, "Prospecto", 9 de marzo de 1843. 
una larga y desnaturalizada lucha contra la religión, buscan en ella un abrigo contra sí mismos [...] sienten el vacío que han dejado ellos en la sociedad, y poniendo bajo sus pies los principios del siglo XVIII, quieren manifestarse mejores y más sabios en el siglo XIX" ${ }^{33}$. En un mundo lanzado vertiginosamente hacia el cambio, la religión sería la garantía de estabilidad, de preservación de un orden, en el movimiento que conduce al progreso guiado por la Providencia. El catolicismo, "mientras que todo lo que le rodea se muda, él permanece inmoble; en lo que no se ve otra cosa que la manifestación sucesiva de los designios eternos" 54 . Para confirmar su línea asociada al debate de temas doctrinarios, desde su número 3, agregó en su epígrafe, la frase "periódico filosófico, histórico y literario".

La Revista hizo propia una interpretación del concepto de filosofía, compatible con la noción de progreso. Obviamente este se entendió en términos distintos al concepto de filosofía racionalista o dieciochesca que había merecido la condena eclesiástica por anticatólico. La filosofía, conducida por la Iglesia católica, "en su marcha progresiva en medio de las visicitudes humanas..." es garantía contra "el furor de la tiranía y del poder (pues) señoreándose sobre lo que pasa, participa de la inmovilidad de lo eterno" 55 . Ello explica que el diario El Progreso haya celebrado su fundación porque sus autores habrían comprendido, finalmente, que "la filosofía reconoce hoy al cristianismo su benéfico poder civilizador, habiendo cesado ya el antagonismo que con sus luchas tuvo agitado el mundo civilizado en el pasado siglo". En consecuencia, felicitaban al nuevo periódico por haber aceptado la "armonía entre la religión y la filosofía”, y por haber comprendido que la filosofía del siglo XIX no pretendía destruir sino construir un orden nuevo ${ }^{56}$. No obstante, en lo que La Revista no transó fue en su denuncia de los males de la filosofía separada de la fe, convertida en "el azote más terrible y destructor de la humanidad, como lo comprueban la historia y la experiencia” cuando ha declarado la guerra al catolicismo, en clara alusión al siglo XVIII ${ }^{57}$. Definida como "la ciencia humana", se encuentra descarriada, y solo si

\footnotetext{
La Revista Católica, "Mirada religiosa sobre la Europa", 9 de marzo de 1843.

54 La Revista Católica, "Influencia del Catolicismo en el orden social", 15 de julio de 1844. 33.

55 La Revista Católica, "Tendencias de la Impiedad”, 18 de febrero de 1846. 88.

56 El Progreso, "La Revista Católica", 10 de marzo de 1843.102.

57 El Progreso, "La Revista...".
} 
"vuelve a buscar el eslabón de oro que la unía con la ciencia divina" reencontrará el camino hacia "las doctrinas reales" 58 . En un número de aniversario, y resumiendo su cruzada de los primeros dos años, La Revista se declaró convencida de que "[...] a vista de las costosas experiencias de 19 siglos, de las quiméricas teorías y de los repetidos e infructuosos ensayos de la humana filosofía no existe ni puede existir elemento civilizador más eficaz y poderoso que la Religión católica [...]". Ella es el "rico venero de prosperidad y bienestar" 59 . Gracias a la religión, los gobernantes entendían que son "unos cooperadores de la divina providencia; y que a su imitación, deben gobernar a los hombres de un modo desinteresado, generoso y benéfico" ${ }^{60}$. La religión sería también un antídoto contra "los atentados y funestas escenas de las revoluciones"; ella muestra la virtud, y consolidando las instituciones, asegura "la felicidad pública"61.

Estas reflexiones son representativas del esfuerzo eclesiástico por no perder el campo cultural buscando armonizar filosofía e idea de progreso como lo exigía la generación republicana. No obstante, algunos episodios conflictivos sucedidos en los años 40 despertaron dudas respecto de la posibilidad de que los conceptos pudieran interpretarse simultáneamente en clave laica y religiosa, especialmente desde que la crítica antieclesiástica radicalizó sus posiciones anticatólicas. La publicación en 1844 de Sociabilidad Chilena por Francisco Bilbao, quien se reconoció discípulo de Lamennais, fue tal vez el detonante más claro de que un espacio, hasta ese momento, inmune a la crítica, dejaba de serlo. El texto asociaba a la religión católica con el pasado, a España con la "Edad Media", a Cristo tan solo con los profetas ${ }^{62}$. El debate iniciado ese mismo año en torno a la obra del francés Aimé Martin, De la educación de las madres de familia, o de la civilización del género humano por las mujeres que La Gaceta de Valparaíso había decidido reimprimir, sirve también para explicar el quiebre entre la prensa laica y La Revista Católica, no

58 La Revista Católica, "Reacción de la ciencia del siglo hacia las ideas religiosas", 1 de julio de 1843.7

59 La Revista Católica, "La Revista Católica en los años 43 y 44", 31 de diciembre de 1844. 50.

60 La Revista Católica, "Influencia del Catolicismo en el orden social" (continuación), 24 de julio de 1844. 34

61 La Revista Católica, "Influencia del Catolicismo en el orden social" (continuación), 1 de agosto de 1844.35

62 A. Stuven, La Seducción... 
ajeno a la ruptura que en Francia se había desatado luego de la condena papal a Lamennais y la preponderancia que asumía entre los intelectuales el humanitarismo ${ }^{63}$.

El órgano católico condenó la publicación de Martin por negar la existencia del infierno, por atentar contra la unidad moral al oponer la "civilización de todos los pueblos de la tierra" a la afirmación católica de que solo hay salvación en su Iglesia, por oponer el espíritu del cristianismo y de tolerancia al catolicismo y, finalmente también, por su visión sobre la virginidad de la mujer y su derecho al placer carnal. Participaron de la polémica tres periódicos, siendo la actitud de El Progreso la que molestó más al periódico eclesial por su postura de tolerancia hacia la separación entre moral y dogma. Ante el ataque de este liberalismo que por anticlerical parecía anticatólico, también El Mercurio saltó a la palestra defendiendo el rol social de la religión y retomando el ataque a la filosofía. "La historia nos muestra que como es imposible la existencia de un pueblo ateo, lo es también la de un pueblo literato o filósofo", escribió. También: "La religión es la filosofía del pueblo". El cristianismo es "el código popular de la democracia". El error de la filosofía se extendía también a su afán de intromisión sobre la historia, al intentar "someter a la ley destructora del tiempo, la religión evangélica, destinada a crecer con él y acompañar a la civilización en sus últimos triunfos" ${ }^{64}$.

Asimismo, el diario se sumó a la defensa del rol social de la religión y su superioridad sobre la filosofía, y criticó la influencia del pensamiento francés sobre la juventud. Los jóvenes, a juicio del diario, no comprendían "las verdaderas tendencias del movimiento inteligente de esa nación (Francia), cuyas revistas plagian tan locamente entre nosotros, como si las luces de la civilización francesa pudieran alumbrar nuestras atrasadas costumbres y los intereses sociales a cuyo servicio debe estar la prensa consagrada" ${ }^{65}$. No parecía conveniente que los chilenos siguieran las huellas de la reflexión europea, sino más bien responder a las necesidades de un país aún en tránsito hacia el progreso. En una serie de 10 artículos, el diario repasó detalladamente los errores de la filosofía

63 M. C. Galfione, Profetas de la revolución: Echeverría, Alberdi, Bilbao y los aportes de la izquierda humanitarista francesa, Tesis para optar al grado de doctor con mención en Ciencias Sociales y Humanas, Universidad Nacional de Quilmes (Buenos Aires, 2009).

64 El Mercurio, art. VII, 24 de julio de 1844

65 El Mercurio... 
del siglo XVIII, así como la oposición entre cristianismo, socialismo, humanitarismo y liberalismo ${ }^{66}$. La filosofía, escribió el articulista al final de la serie, "no tiene principios fijos que propagar, y que resistan a las mudanzas de los tiempos y a los climas... de cada civilización”. Hispanoamérica, "dominada más por las tradiciones del pasado que por las ideas de la civilización moderna", no estaría en condiciones de emular a los franceses pues solo "se llama republicana sin ser civilizada" ${ }^{67}$. La educación, eslabón que uniría a las repúblicas con la civilización, estaba aún lejos del horizonte chileno. Las frases son elocuentes de la intención de limitar la influencia de la filosofía por su carácter impermanente frente a una religión inmóvil, como lo afirmara Mirari Vos, pero también conducida progresivamente por la Providencia ${ }^{68}$. El Mercurio dedicó especial esfuerzo a la relación fructífera entre civilización, progreso y fe cristiana; entre unidad de creencias y orden social.

Los artículos de El Mercurio fueron un anticipo del giro crecientemente combativo que tendría el discurso eclesiástico a medida que las nuevas generaciones fueran incorporando los postulados de un liberalismo más doctrinario e incluso del socialismo y humanitarismo. Hacia 1845, el tono del debate en torno a la relación entre religión y filosofía permite identificar un nuevo momento de mayor tensión justificado por el creciente anticlericalismo, al que se sumaron órganos de prensa. Ese año, El Progreso, exponiendo su nueva línea editorial, distante de aquella que celebró la aparición de La Revista Católica, publicó que el triunfo de la civilización había quedado zanjado a favor de la filosofía, "de modo brillante en el siglo XVIII", condenado por "el absolutismo pontificio". El diario se preguntó: “¿Qué pruebas más elocuentes se quieren de la tendencia filosófica porque abogamos?”" 9 . El Progreso intentó plantar una cuña entre la asociación de catolicismo con cristianismo, eliminando a la Iglesia del debate en torno al progreso ${ }^{70}$. La Revista se defendió

66 "El Contrato Social es hoy todavía seguido por los hijos del fanatismo político que se supone depositario de las creencias liberales que deben civilizarnos", El Mercurio, artículo III, julio 5, 1844.

67 El Mercurio, art. IX.

68 El Mercurio. "Del cristianismo católico considerado como elemento de civilización en las repúblicas hispanoamericanas", julio 1, 1844. El título habla por sí solo de la defensa de la relación entre cristianismo y catolicismo.

69 El Progreso, "La Iglesia y el Estado", 18 de julio de 1845.

70 El Progreso, 21 de marzo de 1843, 111. 
apropiándose nuevamente de los principios democráticos: “... la mejor base de la democracia es la religión católica; porque ella nos da las más sublimes nociones sobre la dignidad, la libertad y la igualdad del hombre [...]", formando "el espíritu de una buena república"71. En una serie de artículos titulados "La religión considerada como la base de la civilización", La Revista consignó a la religión católica como "único y poderoso regulador [...] de la máquina social", poderoso contra "la opresión y la anarquía [...], el despotismo de los que gobiernan y [...] de la multitud"72.

En este nuevo momento, la Iglesia asumió el contexto de efervescencia social que acompañó la reelección del presidente Bulnes y las frecuentes apelaciones al artesanado, sosteniendo que en el terreno del control social, la filosofía y la política serían impotentes, pues solo la religión podía ejercer como freno al desasosiego de las masas. Todo el edificio de la civilización estaría entonces cimentado sobre la verdad religiosa. La referencia hacia la libertad sobre la que se fundan "las modernas sociedades" es fruto de la "adopción divina". A las creencias religiosas e "ilustradas" que conforman el cristianismo se deben el desarrollo de la libertad, "produciendo en menos de tres siglos más número de emancipados que en cuarenta no había verificado la civilización antigua"73. En definitiva, en su respeto a la libertad, la Providencia encendió "una luz inextinguible y segura que sirviese de faro a la razón en el oscuro y proceso piélago de la vida. Esta luz es la religión”74 . Su labor de guía del curso que debe seguir el progreso convierte a la religión en "el resorte supremo" que regula el poder político.

Entre los recursos combativos a que apeló la Iglesia figuran los documentos doctrinarios que elaboraba el clero, entre los cuales destacan especialmente los discursos de incorporación a las facultades de la Universidad de Chile. En 1846 el presbítero Pascual Solís ingresó como miembro a la Facultad de Teología disertando sobre la importancia de los institutos religiosos, "[...] asociaciones civilizadoras que trabajan en

71 La Revista Católica, 15 de julio de 1844, 33.

72 La Revista Católica, "La Religión considerada como la base de la civilización", I, artículo $2^{\circ}$. 20 de enero de 1847. 113.

73 La Revista Católica, "La Religión considerada como la base de la civilización", II, artículo $2^{\circ} .10$ de febrero de 1847. 115.

74 La Revista Católica, "La Religión considerada como la base de la civilización", III, artículo $2^{\circ} .20$ de marzo de 1847.119. 
silencio en la reconstrucción del edificio social, en neutralizar la fuerza de los principios disolventes [...]"75. Francisco de Paula Taforó, en la misma tribuna, al año siguiente, declamó a favor de las "instituciones liberales" y del "gobierno ilustrado" del país al mismo tiempo que alertó contra la incredulidad creciente, argumentando que “... cuando se trata de defender la causa de la fe es preciso batirse en el mismo terreno, y aun con las mismas armas del adversario", lo cual explica su referencia estratégica al liberalismo. El clérigo se hizo cargo de la resignificación que había sufrido la filosofía en Europa, redefiniendo al enemigo: Este no estaría ya en el campo de la "filosofía sólida y austera", sino en el romanticismo: "No, sres., las fábulas y los poemas [...] la música con sus armonías fascinadores y la poesía con sus arrobadoras cadencias, son las armas que asestan al corazón de una inexperta juventud [... ${ }^{776}$. El derrotero romántico, incluía al pueblo, en un distinto registro del credo liberal, como víctima del progreso colectivo y favorito en el designio providencial; se trataba de un camino que conducía hacia el espiritualismo y el humanitarismo laico.

Además del romanticismo, el eclecticismo, el humanitarismo y el panteísmo fueron blanco de ataque por las fuentes eclesiásticas. Mientras el liberalismo acusaba al clero de "jesuitismo" por su adhesión al papado, el jansenismo fue condenado como "secta esencialmente hipócrita" y acusado de defender "perniciosas teorías", por el presbítero José Manuel Orrego ${ }^{77}$. En el mismo acto en la Universidad, Hipólito Salas arremetió contra la filosofía, en un texto elocuente: "Yo no temo afirmarlo, señores, reconocer en la razón y en la filosofía la regla inalterable y segura de las creencias y de los deberes, sería socavar por sus cimientos el majestuoso edificio de la fe y de las costumbres, y hundir en un solo abismo al individuo con la familia y a la religión con la sociedad"78. En

75 Discurso pronunciado por el presbítero don Pascual Solís, al incorporarse en la Universidad de Chile, el 18 de enero de 1846, como miembro de la Facultad de Teología, Anales de la Universidad de Chile (Imprenta Universitaria, Santiago, 1846), Tomo III, 58.

76 Discurso pronunciado por el presbítero don Francisco de Paula Taforó a su incorporación solemne en la Universidad, como miembro de la Facultad de Teología, el día 14 de noviembre de 1847, Anales... Tomo IV, 158.

77 Discurso pronunciado por el presbítero don José Manuel Orrego a su incorporación solemne en la Universidad como miembro de la Facultad de Teología, el 26 de diciembre de 1847, Anales... 1847, tomo IV, 1.

78 Discurso pronunciado por el presbítero don José Manuel Orrego, Anales... 191. 
la misma línea, solo meses antes, en la misma facultad, el presbítero Ramón Valentín García había afirmado que "[...] el cristianismo es la única civilización avanzada y el principio de todo progreso científico y social. La noción católica no puede ser sustituida por la noción racionalista: por esto el espíritu filosófico, abandonado a sí mismo, niega la existencia de todo lo demás" ${ }^{\prime 7}$.

LA INTERRUPCIÓN DEL DIÁlOGO: LA CONDENA PONTIFICIA AL PROGRESO, AL LIBERALISMO Y A LA “MODERNA CIVILIZACIÓN"80

El arzobispo Valdivieso había conducido a La Revista por una vía encaminada a afianzar la unión indestructible entre orden social, religión y poder moderador de la Iglesia. Los sucesos franceses de 1848 inauguraron otro momento de distanciamiento entre el republicanismo radical, el liberalismo y el clero. El discurso de incorporación a la Facultad de Teología de Federico Errázuriz marca la inflexión cuando afirma que Europa se encuentra conmovida desde sus cimientos. "Yo no creo que la Francia pueda perfeccionar su régimen gubernativo bajo el sistema republicano con los exagerados principios de democracia que hasta aquí se han proclamado" ${ }^{1}$. Lo más novedoso es que asume el desafío planteado por el romanticismo, y reconoce que los movimientos europeos tienen su origen en problemas sociales; en "la necesidad indispensable de mejorar la condición de la clase pobre de la sociedad”. No obstante, para Errázuriz, la situación del proletariado se origina en "su ignorancia absoluta y en la corrupción de sus costumbres ${ }^{82}$. Como sostiene en otra disertación justamente sobre el artículo $5^{\circ}$ de la Constitución que consagraba el unanimismo católico de la república, José Francisco Echenique, argumentó que, frente al tema de los problemas sociales que el 48 europeo había puesto sobre la mesa, la religión sería la encargada

79 Discurso pronunciado por el presbítero don Ramón Valentín García a su incorporación solemne en la Universidad como miembro de la Facultad de Teología, el día 1 de agosto de 1847, Anales... 1847, tomo IV: 111.

80 Syllabus Errorum. Catálogo que comprende los principales errores de nuestra época señalados en las encíclicas y otras cartas apostólicas de nuestro santísimo señor Pio Papa IX, 1864.

81 Discurso pronunciado por don Federico Errázuriz en el acto de su solemne incorporación a la Facultad de Teología y Ciencias Sagradas de la Universidad Nacional, en sesión pública del 16 de junio de 1848, Anales... 1848, Tomo IV: 96.

82 Discurso pronunciado por don Federico Errázuriz , Anales... 98. 
también de resolverlos, ya que ella “... defiende al débil del poderoso". El orden social aparece reposando en la religión, lo cual justificaría la defensa del unanimismo católico: "Donde hay tolerancia religiosa no hay jerarquía social o verdadera trabazón entre las diversas partes del estado, no hay por consiguiente mancomunidad, ni objeto social, no hay vida, vigor ni fuerza" ${ }^{33}$. Este rol de contención asignaba a la Iglesia un poder frente al Estado que era difícil de desafiar en momentos de inestabilidad como los que auguraba el 48 francés, sin que la clase dirigente chilena, tanto laica como eclesiástica, corriera graves riesgos sociales y políticos.

La preservación del orden social se convirtió así en una de las banderas de lucha del discurso católico en su defensa de las posturas clericales. Sin embargo, la candidatura de Manuel Montt a la presidencia en 1850 puso en evidencia fisuras que atravesaban el mundo católico transversalmente. El ultramontanismo clerical, animado desde la silla vaticana, hizo resurgir, durante la presidencia de Montt, el problema del patronato, y reanimó el conflicto jurisdiccional. Paralelamente, ante la amenaza al orden social, la religión era un recurso que la autoridad consideraba necesaria. "El clero está en el deber, para salvar la sociedad y la iglesia, de declarar una guerra tenaz y santa contra el socialismo", escribía el periódico El Verdadero Chileno en 1850. Agregando que, para combatir a la oposición, "el catolicismo, el gobierno y los hombres de bien" debían actuar al unísono ${ }^{84}$. En este nuevo escenario en que el autoritarismo estatal combatía al clero pero también usaba la religión a su favor, el liberalismo mantuvo la lucha en el frente doctrinario. A ambos, la Iglesia, con estrechos vínculos con el Sumo Pontífice y crecientemente ultramontana, antiliberal e intolerante enfrentó con fuerza en nombre de su independencia y autoridad, especialmente en el campo educacional.

En ese espíritu se insertó el Edicto Pastoral que dirigió el arzobispo Valdivieso al clero y a los católicos, en junio de 1850, denunciando los perniciosos efectos de la Ilustración, en cuyo nombre, escribió, "se aboga por el error". En una condena directa hacia periódicos como El Amigo del Pueblo, acusó a este de "arrancar del corazón del pobre la religión".

83 Disertación sobre el artículo $5^{\circ}$ de la Constitución, que trata de la religión del Estado, presentada ante la Facultad de Leyes por don José Francisco Echenique para obtener el grado de licenciado en dicha facultad, el día 5 de julio de 1849, Anales..., 1849, Tomo VI,

84 El Verdadero Chileno, 4 de julio de 1850, 172. 
Afirmó que "una vez rotos los diques que nuestra santa religión opone al desborde de las pasiones, no puede haber más que confusión, inseguridad y desorden" ${ }^{85}$. En 1852, La Revista Católica publicó un artículo emblemático que revela el nuevo momento en el lenguaje usado por la curia. Bajo el título "Las ideas dominantes", los conceptos de civilización y progreso, tan caros en años anteriores, fueron conceptualizados negativamente, al mismo tiempo que se admitía que "[...] la época es adversa a toda fe [...]"; que "son raros entre los que se precian de seguir la marcha de la civilización que confiesen sin vergüenza su fe"; que hay muchos que "se forman una religión a su antojo...". Ese sería el sino de la "sociedad moderna", en la cual "las ideas se han desquiciado" de tal manera que "el error forma como un aluvión impetuoso". Se diagnosticaba así una civilización que ya no se definía por la fe, y que identificaba el progreso exclusivamente con lo material. "[...] A la sombra de estas ideas alucinadoras se agitan los hombres por alcanzar una soñada perfección y felicidad puramente humana..." ${ }^{\text {. }}$.

En el terreno doctrinario, ciertos hitos marcaron la tendencia explícitamente autoritaria e intolerante que caracterizaría el momento de quiebre en la búsqueda de un lenguaje común entre el mundo laico y eclesial. La llegada de Pío IX al trono de Pedro fue decisiva. En su primera Encíclica, de 1846, Qui Pluribus, el Pontífice había utilizado un tono de condenación hacia las ideas del siglo, preparando su arremetida final en Quanta Cura y el Syllabus de los errores de su tiempo, los cuales encontraron plena aceptación en la Iglesia latinoamericana ${ }^{87}$. En esta primera carta, Pío IX identificó a sus detractores como: "enemigos de la revelación, (que) exaltan el humano progreso y, temeraria y sacrílegamente, quisieran enfrentarlo con la Religión católica como si la Religión no fuese obra de Dios sino de los hombres o algún invento filosófico que se perfecciona con métodos humanos" $"$. No es de extrañar, entonces, que en 1853, el arzobispo Valdivieso, con motivo de una visita apostólica a sus diócesis, ordenara que se le denunciara a quienes

85 R. V. Valdivieso, 29 de junio de 1850. Edicto Pastoral que el Ilustrísimo y Reverendisimo Señor Arzobispo doctor R. V. Valdivieso dirige al clero y pueblo de su arquidiócesis (Imprenta de la Sociedad, Santiago, 1850).

86 La Revista Católica, 24 de diciembre de 1852. 289.

87 Carta Encíclica, Quanta Cura, Pío IX, 8 de diciembre de 1864, Syllabus Errorum, 1864.

88 Carta Encíclica, Qui Pluribus, Pío IX, 9 de noviembre de 1846. 
“[...] por hecho o palabra sean sospechosos de herejía, excomulgados, o que de alguna manera perviertan las costumbres [...]" ${ }^{89}$. El Edicto, que provocó rechazo de la prensa laica y que fue públicamente quemado en Copiapó, es reflejo importante de la pérdida de la intención de diálogo por parte de Valdivieso ${ }^{90}$. Al año siguiente, nuevamente Pío IX reforzó su postura de oposición al racionalismo filosófico. "De ahí que, según su vana opinión, las disciplinas teológicas habrían de ser tratadas de la misma manera que las filosóficas, siendo así que aquellas se apoyan en los dogmas de la fe, a los que nada supera en firmeza, nada en estabilidad; y estas se explican e ilustran por la razón humana, lo más incierto que pueda darse, como quiera que es varía según la variedad de los ingenios y está expuesta a innumerables falacias e ilusiones" ${ }^{\prime 1}$.

La publicación de Quanta Cura y del Syllabus, en 1864, por parte de Pío IX, cerró un ciclo de relación entre el frente eclesiástico y el laico, este último crecientemente influido por el Liberalismo. Si bien durante los años 40 la Iglesia buscó apropiarse de los conceptos que el liberalismo había consagrado en la arena política, intentando la conciliación entre ellos y la religión, la condenación pontificia selló la alianza de la Iglesia chilena con el ultramontanismo, y dejó al liberalismo en la trinchera contraria. Llevando al apogeo su tono negativo hacia las ideas del siglo y hacia lo que calificó como "época tan desgraciada”, el Papa condenó tanto la libertad de conciencias como de culto, al comunismo y socialismo, la dependencia eclesial de la autoridad civil, el protestantismo, la masonería y el indiferentismo religioso. Frases como "opiniones depravadas", "perversas doctrinas" marcaron el tono de un documento que denunciaba la "conspiración de enemigos contra el catolicismo", y que fundamentalmente afirmaba que "la potestad real no se dio solamente para gobierno del mundo, sino también y sobre todo para la defensa de la Iglesia" 92 . Negaba, asimismo, que el pontífice pudiera conciliar con el progreso, el liberalismo y la cultura moderna.

89 "Edicto de la visita Arzobispal", num. 33, en Boletín Eclesiástico (Imprenta de la Opinión, Santiago, 1861) Tomo 2.

90 J. FernÁndez, "Anticlericalismo, regionalismo y movilización social. El motín anti-arzobispal de Copiapó en 1853", Revista de Historia (2008-2009), vol. 18-19, 197-211.

91 Alocución Apostólica, Singulari Quaedam, 9 de diciembre de 1854.

92 Carta Encíclica, Quanta Cura, op. cit. 
Los discursos leídos ante la Universidad de Chile recogieron el nuevo rumbo. El presbítero Jorge Montes se propuso, en su discurso de incorporación, refutar el racionalismo, sugiriendo que la historia de la filosofía demostraba sus esfuerzos estériles por dar una solución a los problemas del espíritu humano, los cuales habrían desembocado en "doctrinas disolventes que amenazan conmover el orden religioso y moral". Haciéndose eco de la difusión de los problemas sociales, acusó a las "diversas teorías sobre mejora social" de rechazar al cristianismo por viejo y gastado. Condenando estas teorías, desahució definitivamente la lucha por la definición del progreso. "La hipótesis del progreso indefinido inherente a la humanidad que forma la base común de todas las escuelas socialistas no puede sostenerse en presencia de los hechos". Finalmente, Montes reinstala "la lucha entre razón y fe", y niega toda posibilidad a la filosofía "sin la luz de la revelación" "33. Como sostuvo un tiempo después Miguel María Güemes, la razón solo puede ser útil si conduce a la fe $\mathrm{fe}^{94}$.

\section{REFLEXIÓN FINAL}

El discernimiento pontificio y del clero chileno sobre el signo de los tiempos del siglo XIX había impedido mayor diálogo con el liberalismo, con los cultos protestantes y con las ideologías que tomaban cuenta de la trayectoria de la filosofía racionalista desde el siglo XVIII. El clero había intentado adherir a la idea de progreso durante los años 40, buscando la concordancia entre el designio providencial y la opción racional. No obstante, a medida que el liberalismo fue asignando al progreso autonomía frente a la fe y enfatizando la idea de un futuro impredecible, el clero se escudó en una postura en la cual solo la fe podía regular el tránsito; ella sola garantizaba el orden frente al cambio acelerado que identificaba en las propuestas filosóficas. El recorrido impulsado por el neocatolicismo fue bruscamente interrumpido luego de la condena a Lamennais y por sus derivaciones humanitaristas, cuya conciliación con las posturas eclesiásticas se había tornado inviable.

93 Discurso leído por el presbítero don Jorge Montes, en el acto de su incorporación en la Facultad de Teología y Ciencias Sagradas de la Universidad de Chile, Anales... 1857.

94 Discurso pronunciado por don Miguel María Güemes en la Facultad de Teología y Ciencias Sagradas de la Universidad de Chile, el 30 de abril de 1859, para llenar uno de los requisitos de la incorporación a la Universidad de Chile, Anales ... 1859. 
El contexto explica el desenlace del proyecto de ley sobre tolerancia religiosa que presentó Manuel Antonio Matta al Congreso chileno en 1865. Luego de una larga discusión, su intención de derogar el artículo V de la Constitución que consagraba la religión católica como la única que podía expresarse públicamente, culminó apenas con su reinterpretación, redefiniendo, para permitir su culto, como privados los templos de denominaciones no católicas. Fue una solución pragmática para satisfacer a los inmigrantes, especialmente anglicanos. Los conceptos del progreso, surgidos desde la filosofía ilustrada para definir el horizonte de expectativas de la civilización decimonónica, delineaban senderos incompatibles con la intolerancia ultramontana. Los esfuerzos desplegados por el neocatolicismo para que permanecieran al alero de la religión se encontraron con la intransigencia pontificia y con la oposición de una generación que se escapaba del alero eclesiástico. Tampoco habían conseguido asimilar exitosamente el progreso moderno de las ciencias y el método de pensamiento que lo había hecho posible; no había podido formular una "ciencia católica". Sin embargo, paralelamente a la lucha política por su independencia, y ante los desafíos planteados por el positivismo, sectores del clero no abandonaron la defensa de la armonía y complementariedad entre filosofía y teología, entre fe y razón. El discurso de Francisco Quintanilla al incorporarse a la Facultad de Teología de la Universidad, el 24 de marzo de 1869 es una demostración de la búsqueda católica de nuevos caminos de conciliación o, más bien, de su resignación frente a los avances del positivismo de separar los dominios del conocimiento científico de la fe. Con el título "Refutación del Tradicionalismo" afirmó los derechos de la razón humana para el conocimiento de las verdades naturales, considerándolas "preámbulo de la fe" ${ }^{95}$ y que la naturaleza del hombre es capaz de un progreso siempre creciente.

La presencia eclesiástica en la esfera pública chilena del último cuarto del siglo XIX se manifestó en dos frentes de acción. Por una parte, en la decisión, especialmente de la intelectualidad clerical, de mantenerse activos en el diálogo con la modernidad y en interpretar sus conceptos en clave conciliatoria con las demandas de una cultura crecientemente cientificista y racionalista; por otra, en la postura ultramontana, inserta en el nuevo momento eclesiástico marcado por el triunfo del papado y el

95 La Revista Católica, 10 de abril de 1869 1049: 89. 
Concilio Vaticano ${ }^{96}$. La primera buscó participar del debate científico, descifrándolo, armonizándolo con una relectura del texto bíblico, y estimulando el encuentro entre ciencia y cultura religiosa. El reconocimiento ultramontano del primado del Papa implicaba una afirmación del carácter sobrenatural de la Iglesia, lo cual para los obispos significó que esta gozaba de plena autonomía y debía en consecuencia ser independiente del Estado. Fue este frente el que recrudeció el conflicto que ocuparía al clero y a la clase política chilena, sembrando al interior del catolicismo una división política de amplia repercusión histórica, y que extendió su influencia hacia el siglo siguiente. La lucha antiliberal se convirtió así en la lucha contra el Estado laico, consagrando la paradoja de que luchando por la catolicidad del Estado contribuyó a su desacralización ${ }^{97}$. Sin embargo, el catolicismo no abandonó el campo cultural a pesar del desgaste de su lucha por su independencia. La continua presencia del catolicismo en la esfera pública chilena no se puede explicar completamente por la existencia de ambos frentes, aunque en alguna medida la existencia permanente de un debate intelectual que no puede prescindir de la religión ha impedido que el laicismo eche raíces profundas en el país.

96 Entre los 747 participantes, hubo 48 prelados de América Latina, los cuales dieron su apoyo al Pontífice, votando unánimemente por el dogma de la Infalibilidad Papal.

97 R. Krebs, "El pensamiento de la iglesia frente a la laicización del estado en Chile, 1875-1885”, en R. Krebs, S. Correa, A. Riquelme, S. Serrano, P. Arancibia, M. E. Pinto, Catolicismo y Laicismo, Seis estudios (Ediciones Nueva Universidad, Santiago, 1989). 
